ARTICLE

Received 1 Dec 2014 | Accepted 20 Jul 2015 | Published 3 Sep 2015

DOl: $10.1038 /$ ncomms 9113

OPEN

\title{
Abscisic acid transporters cooperate to control seed germination
}

Joohyun Kang ${ }^{1,2}$, Sojeong Yim² ${ }^{2}$ Hyunju Choi ${ }^{2}$, Areum Kim² ${ }^{2}$ Keun Pyo Lee ${ }^{3}$, Luis Lopez-Molina ${ }^{3, \star}$, Enrico Martinoia ${ }^{1,2, \star} \&$ Youngsook Lee $2,4, \star$

Seed germination is a key developmental process that has to be tightly controlled to avoid germination under unfavourable conditions. Abscisic acid ( $A B A)$ is an essential repressor of seed germination. In Arabidopsis, it has been shown that the endosperm, a single cell layer surrounding the embryo, synthesizes and continuously releases $A B A$ towards the embryo. The mechanism of $A B A$ transport from the endosperm to the embryo was hitherto unknown. Here we show that four AtABCG transporters act in concert to deliver $A B A$ from the endosperm to the embryo: $A t A B C G 25$ and $A t A B C G 31$ export $A B A$ from the endosperm, whereas AtABCG30 and AtABCG 40 import ABA into the embryo. Thus, this work establishes that radicle extension and subsequent embryonic growth are suppressed by the coordinated activity of multiple ABA transporters expressed in different tissues.

\footnotetext{
${ }^{1}$ Institut für Pflanzenbiologie, Universität Zürich, Zollikerstrasse 107, 8008 Zürich, Switzerland. ${ }^{2}$ POSTECH-UZH Global Research Laboratory, Division of Molecular Life Sciences, Pohang University of Science and Technology, Pohang 790-784, Korea. ${ }^{3}$ Départment de Biologie Végétale, Université de Genève, 1211 Geneva 4, Switzerland. ${ }^{4}$ Division of Integrative Biology and Biotechnology, POSTECH, Pohang 790-784, Korea. ${ }^{\star}$ These authors contributed equally to this work. Correspondence and requests for materials should be addressed to Y.L. (email: ylee@postech.ac.kr).
} 
S eed germination is tightly controlled in plants. Arabidopsis seeds exhibit primary dormancy, a trait whereby germination of freshly produced seeds is blocked even under favourable germination conditions ${ }^{1,2}$. Many studies have sought to decipher the complex regulatory network that controls seed germination, and it is apparent that abscisic acid (ABA) and gibberellins (GAs) antagonistically regulate seed germination in both dormant and non-dormant seed $3^{3-7}$. Whereas ABA represses seed germination, GAs promote $\mathrm{it}^{2,8,9}$. In non-dormant seeds, environmental parameters, such as light quality, temperature or water potential, determine the endogenous production of $\mathrm{ABA}$ and $\mathrm{GA}^{10-12}$. Recent work has shown that GAs promote germination by negatively regulating ABA levels ${ }^{13}$, which stimulate the production of germination repressors, such as transcription factors $\mathrm{ABI} 3$ and $\mathrm{ABI} 5$ (refs 12-15). GA promotes the proteasome-mediated destruction of DELLA factors that promote endogenous ABA accumulation, leading to seed germination ${ }^{12,13}$.

Dormant seeds typically block germination by maintaining high levels of $\mathrm{ABA}$ on imbibition ${ }^{16}$. Accordingly, mutant seeds unable to synthesize $\mathrm{ABA}$ lack dormancy; that is, they germinate precociously and may even germinate while still attached to the mother plant ${ }^{17}$. This phenomenon, termed vivipary, results in economic loss in crop species. Arabidopsis natural accessions display markedly different dormancy levels: the Cape Verde Island (Cvi) ecotype exhibits much stronger dormancy at harvest than the Columbia-0 (Col-0) or Landsberg erecta (Ler) ecotypes $^{18,19}$. These ecotypes differ in ABA content in the dry seed and the speed of ABA degradation on imbibition ${ }^{20}$. Quantitative trait loci involved in the delay of germination have been identified by comparing the Cvi and Ler ecotypes ${ }^{21,22}$, and some of the loci have been suggested to be related to $\mathrm{ABA}$ signalling or GA sensitivity ${ }^{21-23}$.

One intriguing and poorly understood aspect of seed physiology is the spatial and temporal regulation of $\mathrm{ABA}$ transport on seed imbibition. The Arabidopsis seed consists of an embryo, an active endosperm layer surrounding the embryo, and an outer layer of dead tissue, the testa, of maternal origin ${ }^{24}$. A former study indicated that in dormant seeds, ABA is produced by both the embryo and endosperm ${ }^{25-28}$. More recent studies revealed that some inhibitory compounds produced by tissues surrounding the embryo are responsible for dormancy ${ }^{29-31}$. Elegant experiments conducted by Bethke et al. ${ }^{25}$ further showed that the endosperm layer is responsible for most, if not all, of the germination-repressive activity in Arabidopsis. Recently, Lee et al. ${ }^{32}$ developed a seed coat bedding assay (SCBA) that allows the monitoring of growth of dissected embryos cultured on a layer of seed coat bedding, which consists of testa and endosperm. This assay is useful to identify components active in either endosperm or embryo that control germination. Indeed, this assay provided direct evidence that $\mathrm{ABA}$ is released from the endosperm of dormant seeds on imbibition to inhibit embryo development. The SCBA was used to further show the importance of the endosperm in non-dormant seeds. An early far-red light pulse that blocks germination involves phytochrome $\mathrm{B}$ ( $\mathrm{phyB}$ ) inactivation in the endosperm, which blocks the expression in GA biosynthesis genes in the endosperm, and induces $\mathrm{ABA}$ release towards the embryo $^{33}$. Furthermore, recent work suggested that in $g a 1$ seeds, which are unable to synthesize GA, the endosperm also releases $\mathrm{ABA}$ to block germination ${ }^{34}$.

However, how $\mathrm{ABA}$ is transported between the endosperm and embryo in seeds remains poorly understood. Until recently, it was assumed that $\mathrm{ABA}$, being a weak acid $\left(\mathrm{p} K_{\mathrm{a}}=4.9\right)$, passes through biological membranes via passive diffusion when protonated, and is then trapped in the dissociated form in the neutral $\mathrm{pH}$ environment of the cytosol ${ }^{35}$. However, auxin, another weak acid and a potent growth-promoting phytohormone, is not only transported by passive diffusion but also by different types of transporters, which enables the plant to respond accurately and rapidly to environmental changes by adjusting its growth ${ }^{36-38}$. Thus, it is tempting to speculate that a multitude of $\mathrm{ABA}$ transporters coordinately function to deliver $\mathrm{ABA}$ to specific tissues in response to environmental and developmental cues. Indeed, recent studies identifying several $\mathrm{ABA}$ transporters might be a prelude to the discovery of such a network of $A B A$ transporters ${ }^{39-44}$. Two ABC transporters of the ABCG subfamily, AtABCG25 and AtABCG40, export ABA from the vascular bundle and import it into guard cells, respectively $y^{39,40}$. Furthermore, another ABC transporter, AtABCG22, was proposed to function as an $\mathrm{ABA}$ transporter ${ }^{41}$. In addition, several members of the ABA-importing transporter family function as ABA importers at the influorescence stem $^{42,43}$. Recently, a MATE-type transporter has also been reported to act as an ABA efflux carrier in guard cells ${ }^{44}$.

We reasoned that $\mathrm{ABA}$ delivery from the endosperm to the embryo must be accurately controlled and thus might be mediated by multiple coordinated groups of transporters, rather than by diffusion alone. We searched for candidate transporters among the ABCG subfamily of $A B C$ proteins, since this family mediates the efflux and influx of a wide variety of terpenoids ${ }^{45}$, including ABA.

Here we report that four AtABCG proteins function together to deliver $A B A$ from the endosperm to the embryo in mature, imbibed seeds. AtABCG25 and AtABCG31 are mainly localized to the endosperm and export $A B A$ from the endosperm to the embryo, whereas AtABCG30 and AtABCG40 are localized to the embryo and transport $\mathrm{ABA}$ into the embryo. $\mathrm{ABA}$ transport represents an important step in embryo germination and early seedling establishment. Thus, this work demonstrates that a developmental step critical for a plant's survival is efficiently regulated by the coordinated activity of multiple ABA transporters localized in different tissues.

\section{Results}

Screening for candidate ABA transporters in seeds. To select candidate $\mathrm{ABA}$ transporters that regulate seed germination, we first performed an in silico analysis (Arabidopsis eFP browser; http://bar.utoronto.ca/efp/cgi-bin/efpWeb.cgi) of all 43 members of the ABCG subfamily of $A B C$ transporters, and identified 10 genes that are highly expressed in mature seeds. To determine whether any of these candidates may function as ABA transporters within seeds, we screened the mutants for altered patterns of seed germination (Fig. 1). Six of these ten lines did not have an altered germination phenotype. In contrast, the mutant lines of two candidate genes, AtABCG30 and AtABCG31, exhibited clear differences in germination when compared with wild-type seeds. Seeds from freshly collected atabcg31 and atabcg30 mutants germinated earlier than the corresponding wild-type seeds on imbibition without stratification (Fig. 1a,c,e), whereas seed stratification abolished the difference between the mutants and wild type (Fig. 1f). To further investigate whether atabcg31 and atabcg30 mutant seeds exhibit deficiencies in ABA transport, we compared their responses with exogenously added $\mathrm{ABA}$ and found that germination of stratified atabcg31 and atabcg30 seeds was less inhibited by $0.1-1.0 \mu \mathrm{M}$ ABA than was that of the corresponding wild-type seeds (Supplementary Fig. 1a-e). Similarly, we examined whether AtABCG25 and AtABCG40 function as $\mathrm{ABA}$ transporters in seeds. Indeed, atabcg40 seeds exhibited a higher germination rate than the wild type on medium containing $0.1 \mu \mathrm{M}$ ABA (Supplementary 

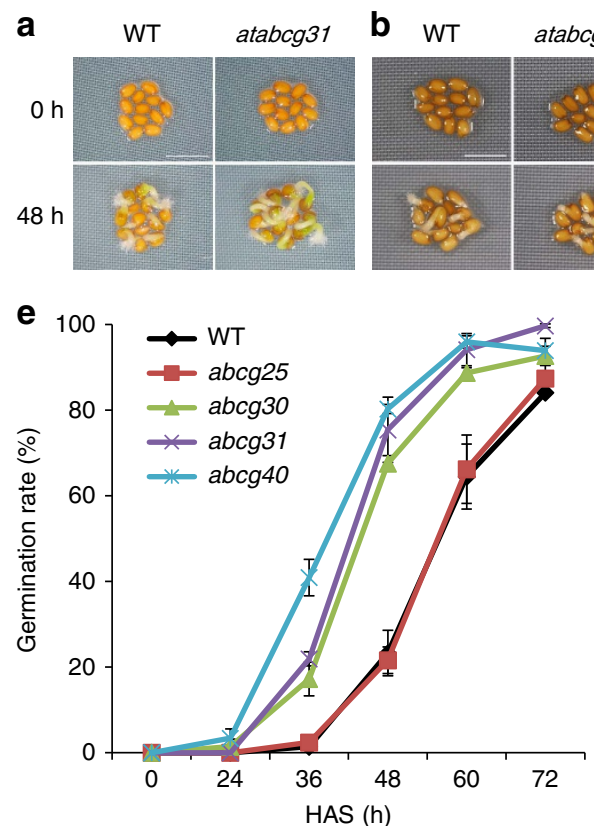
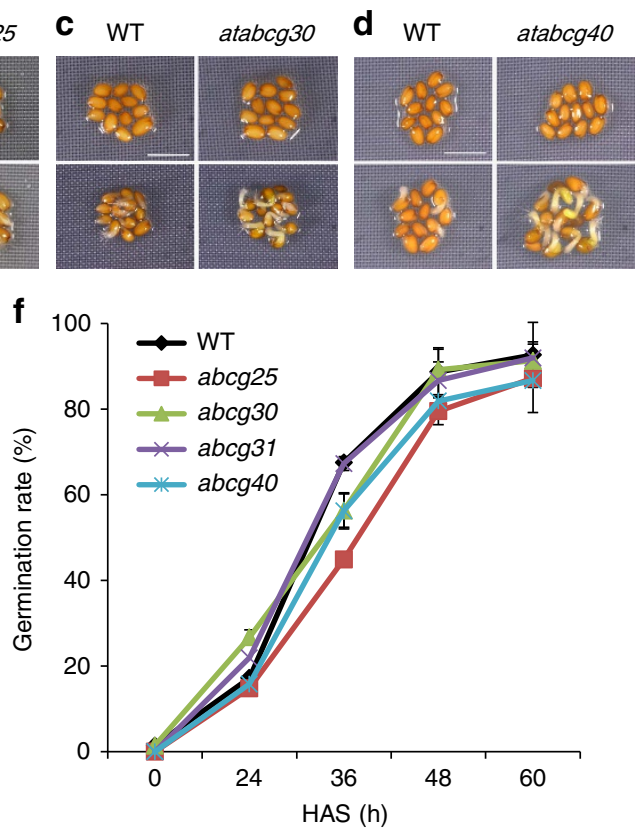

Figure 1 | Seeds of atabcg31, atabcg30 and atabcg40 germinate faster than those of the corresponding wild type (WT). (a-d) Seed germination on $1 / 2$ MS medium without stratification. atabcg31 (a), atabcg30 (c) and atabcg40 (d) mutant seeds germinated faster than the WT, whereas atabcg25 mutant seeds (b) did not. WT seeds collected at the same time were used as the control. Photographs were taken at the start of incubation $(0 \mathrm{~h})$ and $48 \mathrm{~h}$ later. A representative result out of three independent experiments giving rise to similar results is shown. Each experiment consisted of two or three replicates. Scale bar, $1.25 \mathrm{~mm}(\mathbf{a}), 1 \mathrm{~mm}(\mathbf{b}-\mathbf{d})$. (e,f) Germination rate of WT seeds compared with that of atabcg mutant seeds on $1 / 2$ MS medium. Nonstratified (e) or stratified (f) seeds were sowed on $1 / 2$ MS medium, and germinated seeds were determined based on radicle extrusion. Stratification consisted of pretreatment of seeds for 2 days at $4^{\circ} \mathrm{C}$ in the dark. In all experiments, fresh seeds were used, and the sowed seeds were incubated under $16-\mathrm{h}$ light and 8-h dark conditions at $22^{\circ} \mathrm{C}$. Data are mean \pm s.e.m. of three independent experiments with four technical replicates $(N=3, n=4 \times 100$ seeds). HAS, hours after sowing.

Fig. 1b), suggesting that ABA uptake was reduced in these seeds, consistent with a previous report ${ }^{40}$. Furthermore, seeds from freshly collected, non-stratified atabcg40 mutants also germinated earlier than those from the corresponding wild type (Fig. 1d,e). In contrast, the germination of non-stratified, freshly collected atabcg25 seeds was similar to that of wild-type seeds (Fig. 1b,e), even when grown on medium containing exogenous ABA (Supplementary Fig. 1f). This finding contradicts a recent report that showed that the germination of atabcg25 seeds is delayed on medium containing ABA and that AtABCG25 acts as an ABA exporter ${ }^{39}$. This discrepancy may be explained by the ecotype difference and mild nature of the mutant's phenotype, which may depend on plant growth conditions. Given the convincing data presented previously ${ }^{39}$, we continued to include atabcg25 in our studies. Taken together, these results strongly suggest that at least four AtABCG transporters are involved in controlling seed germination.

$A t A B C G s$ are expressed either in the embryo or endosperm. To further explore whether these AtABCG proteins indeed influence germination by regulating $\mathrm{ABA}$ transport within the seed on imbibition, we analysed the transcript levels of the corresponding genes in the endosperms and embryos of mature wild-type seeds. Tissue-specific quantitative reverse transcription-PCR (qRT-PCR) revealed that AtABCG31 was not expressed in dissected embryos, but was expressed at high levels in the endosperm (Fig. 2a). AtABCG25 was mainly expressed in the endosperm and, to a lesser extent, in the embryo (Fig. 2b). This result is consistent with previous in silico data ${ }^{31}$. In contrast, AtABCG30 and AtABCG40 transcripts were strongly expressed in dissected embryos, but only weakly in the endosperm (Fig. 2 d,e). To validate our approach, we performed qRT-PCR with two genes known to be expressed either in the endosperm (AtEPR1, an extensin-like gene involved in seed

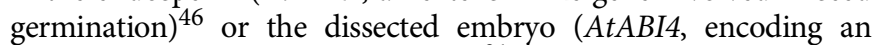
ABA-response transcription factor $)^{31}$. Consistent with previous reports, AtEPR1 transcripts were detected solely in the endosperm, whereas AtABI4 transcripts were detected nearly exclusively in the embryo (Fig. 2c,f). Our analysis of multiple lines of promoter- $\beta$ glucuronidase-expressing plants (Fig. $2 \mathrm{~g}$ and Supplementary Fig. 2a) confirmed the qRT-PCR results; the AtABCG31 promoter was active only in the endosperm layer, and $\beta$ glucuronidase activity driven by the AtABCG30 and AtABCG40 promoters was observed in dissected embryos, but not in the endosperm. Together, these results show that AtABCG31 and AtABCG25 expression is specific to the endosperm, where their protein products may act as ABA efflux transporters. In contrast, AtABCG30 and AtABCG40 expression is specific to the embryo, where their protein products may function as ABA influx transporters. To function as transporters that facilitate ABA flux from the endosperm to the embryo, these four transporters are expected to be localized to the plasma membrane. AtABCG25 and AtABCG40 were previously shown to localize to the plasma membrane $\mathrm{e}^{39,40,47}$. Here we show that AtABCG31 and AtABCG30 are also localized to the plasma membrane of Arabidopsis mesophyll protoplasts and tobacco epidermis cells when transiently expressed under the control of the $35 \mathrm{~S}$ promoter (Fig. 2h and Supplementary Fig. 2b). Co-expression of green fluorescent protein (GFP)-fused AtABCG31 or AtABCG30 with PM-rK (ref. 48), a plasma membrane marker protein (an mCherry fusion of the plasma membrane aquaporin, AtPIP2A), showed complete co-localization of the two ABCG proteins with PM-rK. Plasma membrane localization of AtABCG31 was recently also shown by Choi et al. ${ }^{49}$. 

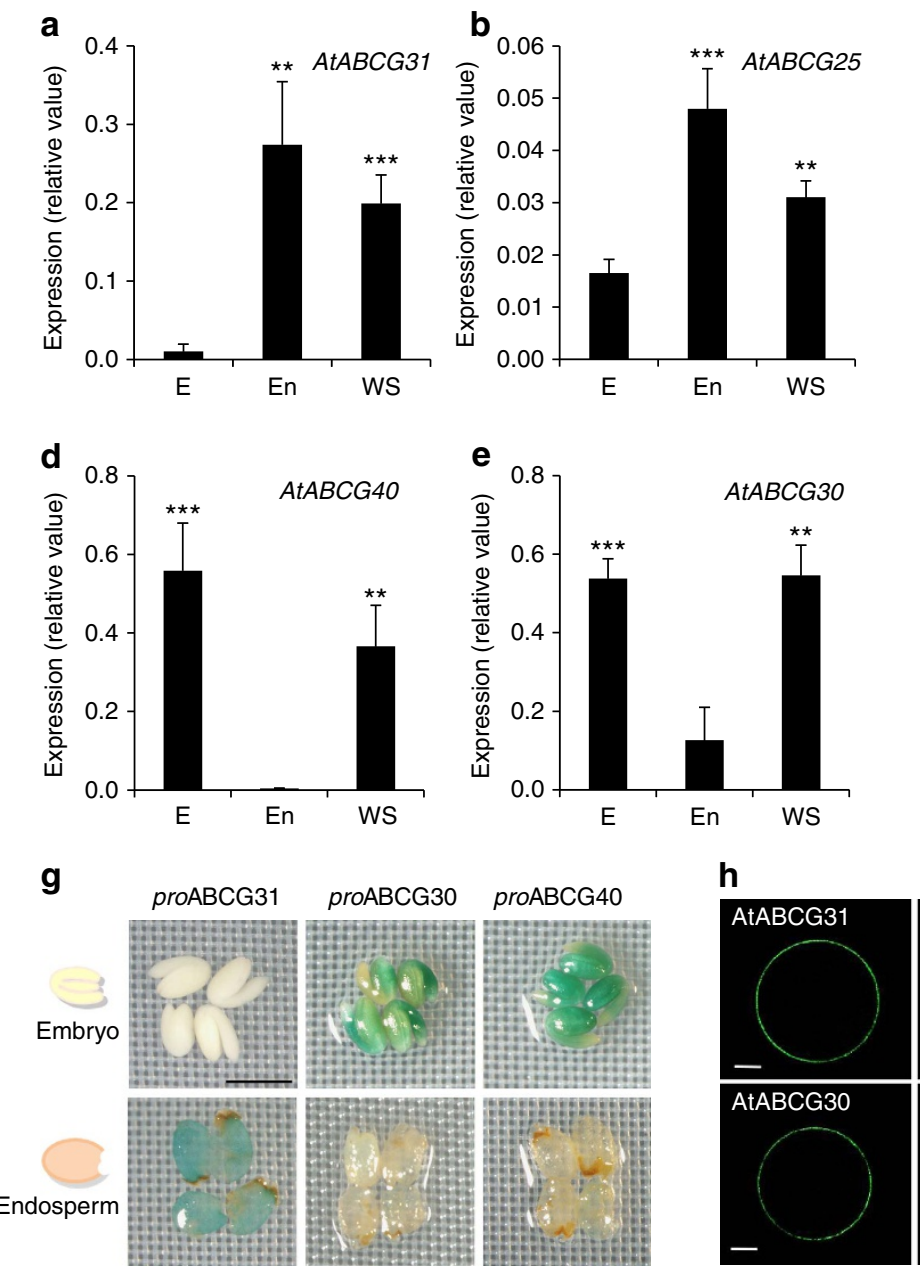
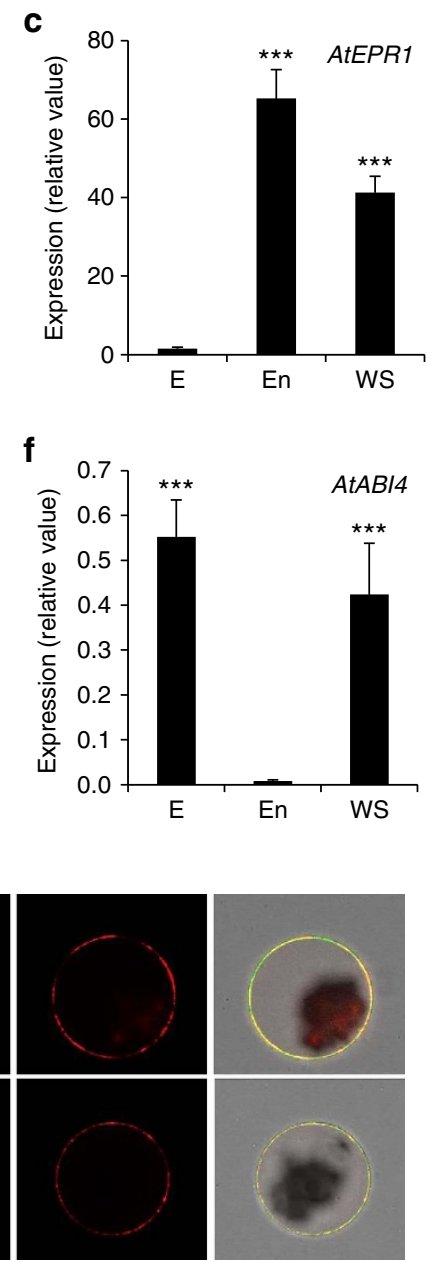

Figure 2 | AtABCG31 and AtABCG25 are expressed mainly in the endosperm, whereas AtABCG30 and AtABCG40 are expressed specifically in the embryo. (a-f) q-PCR analysis of AtABCG31 (a); AtABCG25 (b); AtEPR1, a gene specifically expressed in the endosperm (c); AtABCG40 (d); AtABCG30 (e); and $A t A B / 4$, a gene specifically expressed in the embryo (f). q-PCR was performed using total RNA extracted from dissected embryos or endosperms, or whole seeds of the Col-0 wild type. Data were normalized using AtUbiquitin11. E, dissected embryos; En, dissected endosperms; WS, whole seeds. Data are mean \pm s.e.m. of three independent experiments $(N=3, n=2)$. ( ${ }^{\star \star} P<0.01,{ }^{\star \star \star} P<0.005 ;(\mathbf{a}, \mathbf{b}, \mathbf{c})$ compared with the embryo (E) and $(\mathbf{d}, \mathbf{e}, \mathbf{f})$ compared with the endosperm (En) by Student's t-test). (g) AtABCG31 promoter-GUS ( $p A t A B C G 31::$ uidA) reporter gene activity was detected only in the endosperm, and not in the embryo (left). AtABCG30 promoter-GUS (pAtABCG30::uidA) and AtABCG40 promoter-GUS (pAtABCG40::uidA) activities were detectable only in the embryo and not in the endosperm (middle and right). Embryos (upper panel) and endosperms (lower panel) were dissected from mature seeds and incubated in GUS solution for 30 min. Results representative of 8 (AtABCG30), 12 (AtABCG31) and 9 (AtABCG40) different T3 promoter-GUS lines. Scale bar, $0.8 \mathrm{~mm}$. (h) Plasma membrane localization of AtABCG31 and AtABCG30 in Arabidopsis mesophyll protoplasts. Protoplasts were isolated from Arabidopsis leaves transformed with p35S:::SGFP::AtABCG31 (upper panels) or p35s::AtABCG30::GFP (lower panels) and pd35S::AtPIP2A::mCherry (PM-rK) using polyethylene glycol transformation. The left panel shows the GFP fluorescence of $A B C G$ s, the middle panel the red mCherry fluorescence of the plasma membrane marker PM-rK protein and the right panel shows the merged images of GFP, mCherry and bright-field. Scale bar, $10 \mu \mathrm{m}$. GUS, $\beta$-glucuronidase.

$A B C G 31$ and $A B C G 25$ repress embryonic growth. We next sought to determine whether the embryo or endosperm is responsible for the altered germination phenotype of mutant seeds by performing SCBAs as described by Lee et al. ${ }^{32,33}$. SALK insertion Arabidopsis lines are generated in the Col-0 ecotype, which displays relatively weak and short-term dormancy compared with ecotypes such as Ler or Cvi, for which the SCBA was initially used. As a result, a SCBA using freshly collected Col-0 material may result in less robust embryonic growth arrest results. To better test the role of AtABCG31 and AtABCG25 in controlling embryonic growth, we performed SCBAs in presence of paclobutrazol (PAC), a GA synthesis inhibitor. Lack of GA synthesis promotes ABA accumulation and efficiently blocks embryonic growth in SCBAs ${ }^{13,34,50}$. Indeed, in presence of PAC, seed coats of Col-0 prevented embryonic growth (Supplementary Fig. 3a), and expressed the germination repressor AtABI5 (Supplementary Fig. $3 \mathrm{~b})^{15}$, as effectively as those of Cvi. However, consistent with previous results, PAC did not affect the embryonic growth of dissected embryos or their ability to establish seedlings ${ }^{9}$ (Supplementary Fig. 3c). In this assay, we also used dissected embryos of the aba2-1 mutant, which is defective in ABA biosynthesis and consequently germinates precociously ${ }^{51}$. For quantitative analysis, we measured the angle between cotyledons and radicles as well as radicle length (Fig. 3a,b), as indicators of early embryonic growth. As shown in Fig. 3, seed coats (testa and endosperm) of the atabcg31 or atabcg25 single knockouts did not inhibit the growth or early seedling establishment of the aba2-1 embryo as effectively as did those of the wild type in the SCBA. Our findings for the atabcg25 seed coat are inconsistent with our 
a

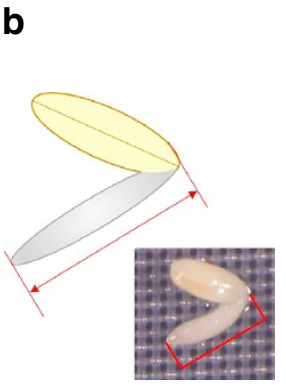

b

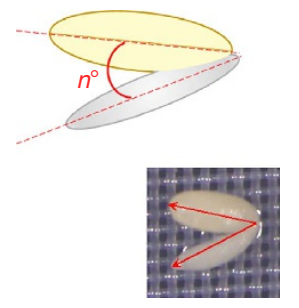

c

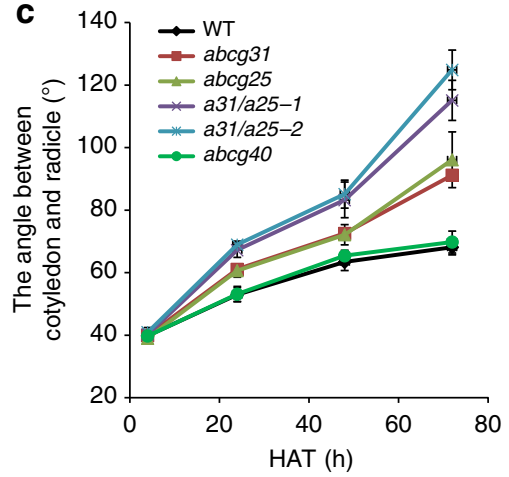

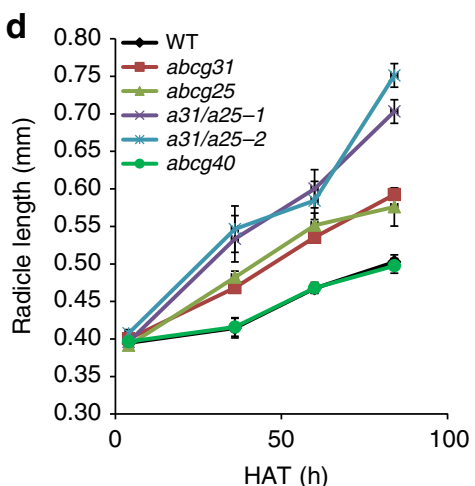

e

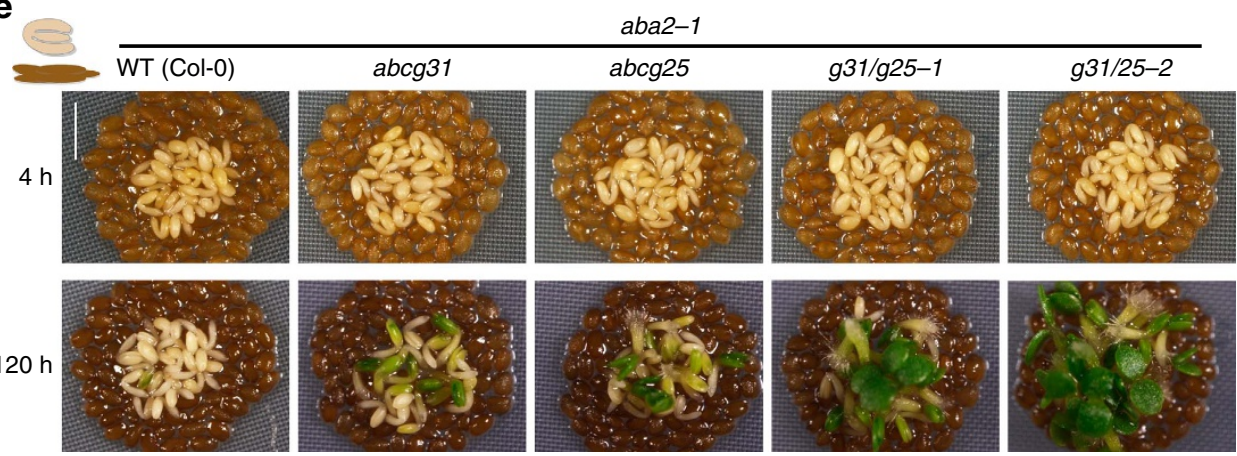

Figure 3 | Seed coats of atabcg31 and atabcg25 repressed the embryonic growth of aba2-1 less effectively than did those of the wild type (WT).

$(\mathbf{a}, \mathbf{b})$ Diagram showing the quantification of the angle between the radicle and the cotyledon and the radicle length, respectively. (a) The angle between the radicle and cotyledon was measured using Axio. (b) Radicle length was measured using Axio. (c-e) Embryos dissected from aba2-1 mutant seeds were placed on a layer of seed coat beddings dissected from the WT (Col-0), atabcg31, atabcg25, atabcg31 atabcg25 (g31/g25-1, g31/g25-2), and atabcg40. The legend in the graph indicates the genotypes of the seeds from which the seed coat beddings were derived. The angle between the cotyledon and radicle (c) and the radicle length (d) of the aba2-1 embryos were measured as indicators of embryonic growth. (c,d) Data are means \pm s.e.m. of $n=108-112$ obtained from three independent experiments. Each experiment was performed in duplicate. Each replicate (one SCB) consisted of 20 embryos ( $N=3, n=2 \times 20$ embryos). (e) Photographs taken $4 \mathrm{~h}$ (top) and $120 \mathrm{~h}$ (bottom) after imbibition. Scale bar, $1.25 \mathrm{~mm}$. HAT, hours after transfer. Results shown are representative of three independent experiments (see Supplementary Fig. 7). Each experiment was performed in duplicate. Similar results were obtained in all experiments.

observation that the germination rate of atabcg 25 whole seeds is similar to that of the wild type (Fig. 1b,e and Supplementary Fig. 4a). This inconsistency may be due to a defect in atabcg25 embryos, which exhibit retarded embryonic growth even when dissected out from the surrounding tissues (Supplementary Fig. 4b). The retarded growth of embryos seems to cancel out the weak inhibitory effect of the endosperm on germination; thus, no aberrations in whole-seed germination are apparent. Reciprocal crossing of atabcg25 with atabcg31 yielded $g 31 / g 25-1$ (atabcg31 pistil; atabcg25 pollen) and g31/g25-2 (atabcg31 pollen; atabcg25 pistil) double mutants, which lack both $\mathrm{ABC}$ transporters. The seed coats and endosperms of the double knockouts ( $(31 / g 25-1$ or $g 31 / g 25-2)$ inhibited the growth and seedling establishment of aba2-1 embryos much less effectively than did those of the single knockouts or the wild type (Fig. 3c-e and Supplementary Fig. 7). These results suggest that atabcg31 and atabcg25 endosperms release reduced amounts of germination inhibitor. In contrast, the seed coat bedding of the other candidate $\mathrm{ABC}$ transporter mutants, atabcg30 and atabcg40, did not differ from those of the wild type in terms of their effect on the development of aba2-1 mutant embryos (Supplementary Fig. 5a, and Fig. 3c,d), indicating that the amount of inhibitor molecules released from the seed coat beddings of wild-type, atabcg30 and atabcg 40 plants was similar.

atabcg30 and atabcg40 embryos are impaired in ABA uptake. We next sought to determine whether AtABCG30 and
AtABCG40 are necessary for embryonic uptake of endospermic ABA. For this purpose, we tested whether atabcg30 and atabcg40 mutants are defective in the embryonic uptake of ABA. We evaluated the growth of atabcg30 (g30), atabcg40 (g40) and $g 30 / g 40$ embryos in SCBAs using seed coats isolated from the highly dormant Cvi ecotype, which were previously shown to efficiently block wild-type embryonic growth in SCBAs ${ }^{32}$. While most embryos of Col-0 wild-type seeds did not grow until $85 \mathrm{~h}$ after imbibition (Supplementary Fig. 5a), the embryos dissected from the seeds of atabcg30 and atabcg40 and the corresponding double-knockout plants (g30/g40) grew and developed to plantlets (Supplementary Fig. 5a and Fig. $4 \mathrm{a}-\mathrm{c}$ ). Thus, these observations indicate that the mutations in AtABCG30 and AtABCG40 genes could not efficiently uptake endospermic ABA released by Cvi seed coats relative to wild-type embryos. We further investigated this possibility by monitoring the development of dissected atabcg30 and atabcg40 embryos in the absence or presence of exogenous ABA. Under control conditions, no difference in the development of embryos was observed between the wild-type and mutant embryos (Supplementary Fig. 5b); however, in the presence of $\mathrm{ABA}$, the development of embryos dissected from atabcg30, atabcg40 and $g 30 / g 40$ double-mutant seeds was inhibited to a lesser extent than those dissected from the wild type (Fig. 4d-f). These observations further indicate that atabcg30 and atabcg40 embryos do not take up the $\mathrm{ABA}$ released from the seed coat bedding of the Cvi ecotype as effectively as does the wild type. 
a

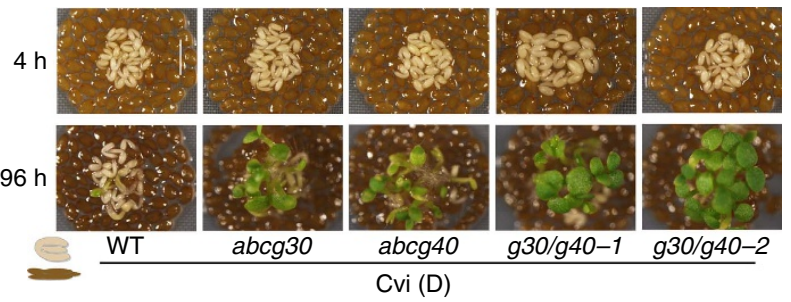

d

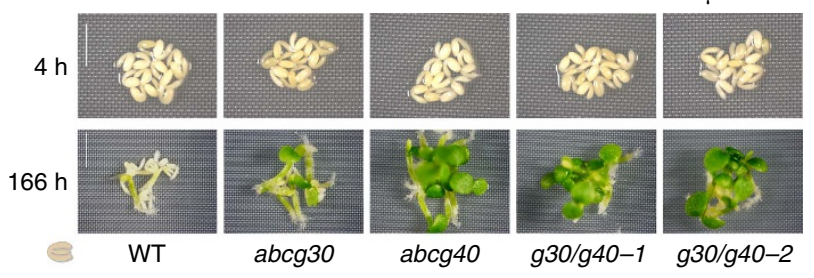

b

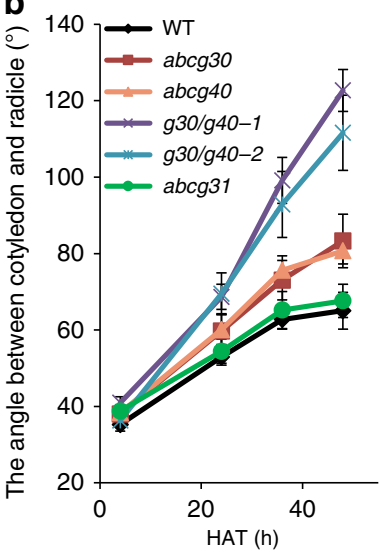

e

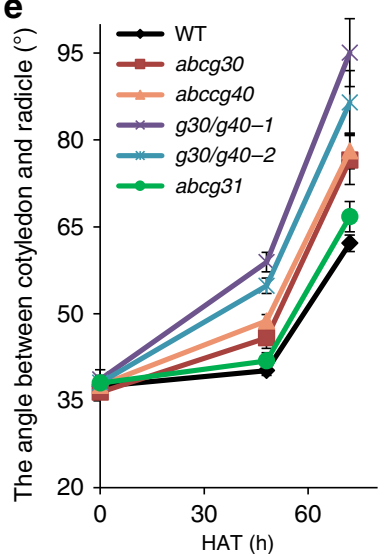

C

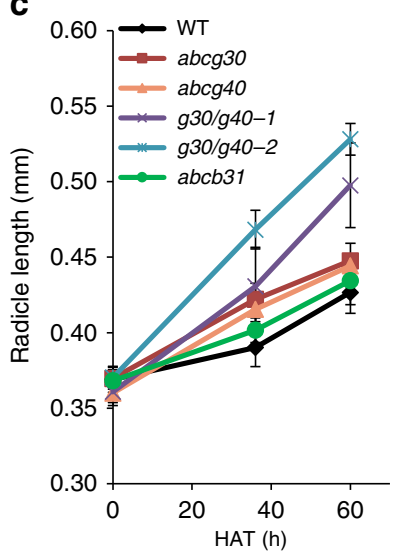

f

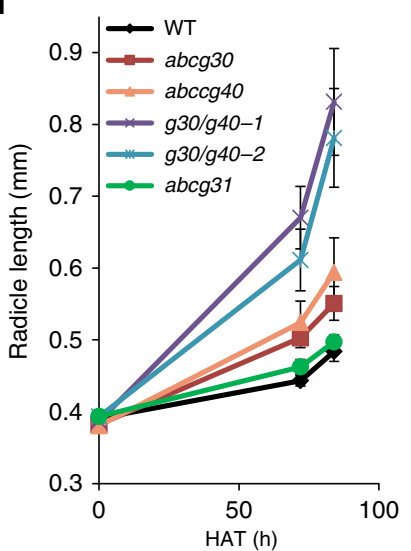

Figure 4 | Dissected embryos of atabcg30, atabcg40 and atabcg30 atabcg40 are less sensitive than the wild type (WT) to endosperm-dependent or exogenous ABA-dependent germination repression. (a-c) Seed coat bedding assay, using embryos dissected from WT (Col-0) or atabcg mutant seeds placed on a layer of seed coat beddings (endosperm and testa) dissected from dormant Cvi seeds (Cvi (D)). (b,c) Data are means \pm s.e.m. of $n=105-109$ obtained from three independent experiments. Each experiment was performed in duplicate. Each replicate (one SCB) consisted of 20 embryos ( $N=3$, $n=2 \times 20$ embryos). (d-f) Embryos dissected from WT (Col-0) and atabcg mutant seeds placed on $1 / 2$ MS medium supplemented with $0.1 \mu M$ ABA. The angle between the cotyledon and radicle $(\mathbf{b}, \mathbf{e})$ and the radicle length $(\mathbf{c}, \mathbf{f})$ were measured as indicators of embryonic growth for each genotype of embryo. $(\mathbf{e}, \mathbf{f})$ Data are means \pm s.e.m. of $n=108$ obtained from three independent experiments. Each experiment was performed in triplicate. Each replicate consisted of 12 embryos ( $N=3, n=3 \times 12$ embryos). In a, photographs were taken at $4 \mathrm{~h}$ (top) and $96 \mathrm{~h}$ (bottom) after imbibition. In d, photographs were taken $4 \mathrm{~h}$ (top) and $166 \mathrm{~h}$ (bottom) after imbibition. Scale bar, $1 \mathrm{~mm}$. (a,d) A representative result out of three independent experiments is shown (six (a) or nine (d) different samples). In all experiments, similar results were obtained.

Four AtABCGs mediate ABA transport in seeds. To directly test whether AtABCG31 and AtABCG25 release ABA from the tissues surrounding the embryo, we removed embryos from the seeds and compared the remaining tissues for secreted and retained endogenous ABA levels. As shown in Fig. 5a,b (with PAC) and Supplementary Fig. 6c,d (without PAC), the tissues surrounding the embryos of atabcg31 and atabcg25 single and double mutants secreted less and retained more ABA. On the basis of these results and previous studies that found that endospermic ABA inhibits germination ${ }^{25,29-33}$, we conclude that AtABCG31 and AtABCG25 contribute to the secretion of ABA from the endosperm. It is interesting that the total ABA content did not differ between the wild type and atabcg31 or atabcg25 (Supplementary Fig. 6e), further indicating the importance of endospermic ABA release to control embryonic growth.

Next, we incubated embryos dissected from the wild type, the atabcg30 and atabcg40 single mutants, and the corresponding double mutants with radiolabelled $\mathrm{ABA}$ and determined the amount of radioactivity taken up after $30 \mathrm{~min}$ at room temperature. Both mutants took up significantly less ABA than the wild type, and the double-knockout mutants took up less than the single knockouts (Fig. 5c). In contrast, embryos incubated in the presence of radiolabelled $\mathrm{ABA}$ on ice did not differ in their ABA contents (Supplementary Fig. 6a). Therefore, the difference in ABA uptake shown in Fig. 5c was mediated by an active transport mechanism and not by simple diffusion. Taken together, these observations further strengthen and lend direct support to the notion that AtABCG30 and AtABCG40 function as endospermic ABA importers. While ABA transport activity has been reported for AtABCG25 and AtABCG40 in heterologous systems ${ }^{39,40}$, it has not been reported for AtABCG30 and AtABCG31. Therefore, to obtain additional evidence that these transporters also catalyse ABA fluxes, we expressed these AtABCGs in yeast and performed ABA transport experiments using the yeast system. Yeast expressing AtABCG31 took up lower amounts of ABA than yeast transformed with an empty vector, while yeast expressing AtABCG30, which was localized to the plasma membrane (Supplementary Fig. 6f), accumulated far more radiolabelled ABA (Fig. 5d). These results are in line with those obtained with embryos and seed coats from the corresponding mutants, indicating that AtABCG31 acts as an exporter, while AtABCG30 catalyses the import of ABA. 
a

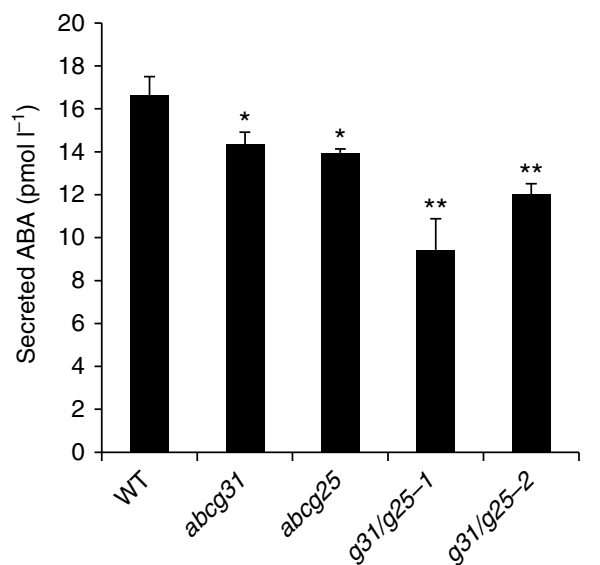

c

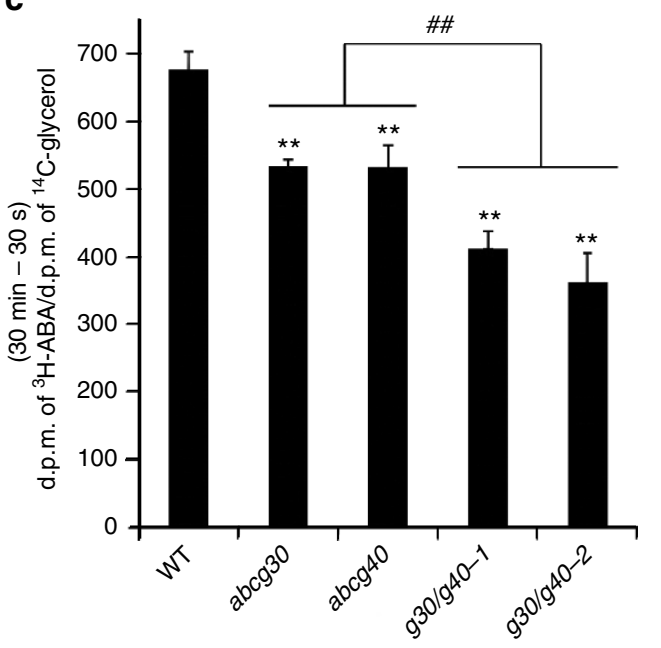

b

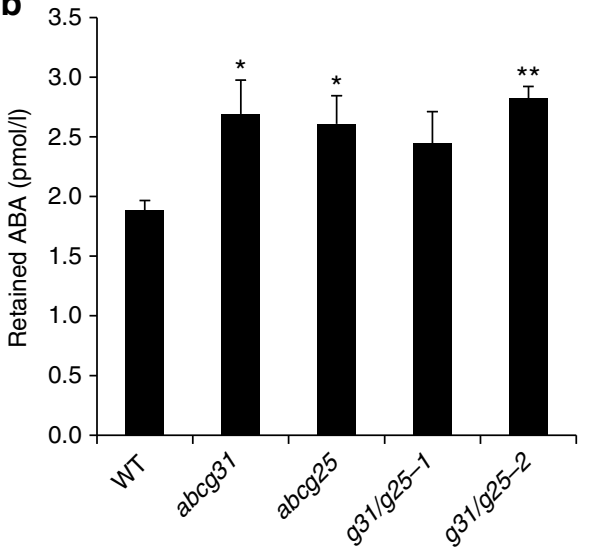

d

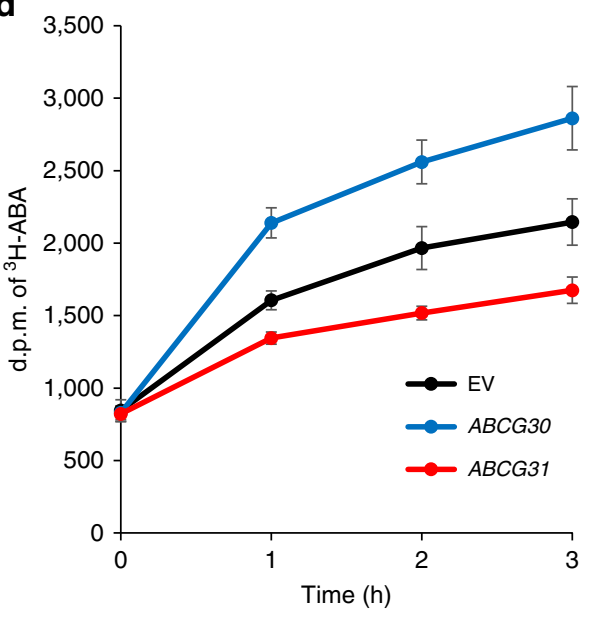

e

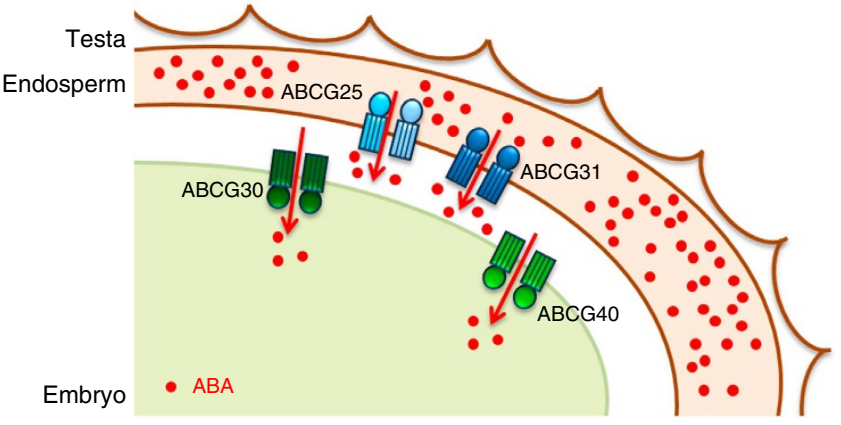

Figure 5 | Four AtABCGs mediate ABA transport in Arabidopsis seeds. (a,b) The endosperms and testa of atabcg mutants release less ABA than do those of the wild type (WT). Endosperms attached to testa were dissected from 500 WT, atabcg31, atabcg25 and atabcg31 atabcg25 (g31/g25-1, g31/g25-2) seeds $24 \mathrm{~h}$ after imbibition on medium containing $10 \mu \mathrm{M}$ PAC. The tissues were then incubated on $1 / 2 \mathrm{MS}$ liquid medium for $24 \mathrm{~h}$ before ABA content was assayed using an ELISA. The aqueous medium was collected for assay of secreted ABA (a), and the remaining tissues were washed three times and extracted to assay the retained ABA (b). (c) atabcg30, atabcg40 and two different lines of double mutant embryos ( $930 / g 40-1$ and $g 30 / g 40-2$ ) accumulated less ABA than the corresponding WT. Accumulation of ${ }^{3} \mathrm{H}-\mathrm{ABA}$ by embryos dissected from WT and mutant seeds during a 30 -min period. Embryos were incubated in a solution of $12.5 \mathrm{nM}{ }^{3} \mathrm{H}-\mathrm{ABA}\left(1.63 \mathrm{Tbq} \mathrm{mmol}^{-1}\right)$ and $17.5 \mathrm{pM}{ }^{14} \mathrm{C}$-glycerol $\left(5.40 \mathrm{GBq} \mathrm{mmol}^{-1}\right)$ at $\mathrm{pH} 6.5$. The radioactivity uptake was normalized to the ${ }^{14} \mathrm{C}$-glycerol d.p.m. (disintegrations per min) value. (d) Time-dependent loading assay of ${ }^{3} \mathrm{H}$-ABA to yeast cells expressing AtABCG31 or AtABCG30, or transformed with the empty vector (EV). Yeast cells were incubated in SG-URA medium containing $50 \mathrm{nM}{ }^{3} \mathrm{H}-\mathrm{ABA}(7.4 \mathrm{kBq}$, $\left.1.63 \mathrm{Tba} \mathrm{mmol}^{-1}\right)$ at pH 6.5. Data are means \pm s.e.m. of $n=12$ from three independent experiments $(N=3, n=4)$. (e) Four AtABCGs participate in the delivery of ABA from the endosperm to the embryo in Arabidopsis seeds. AtABCG31 and AtABCG25 are expressed in the endosperm and secrete ABA from the endosperm to the embryo. AtABCG30 and AtABCG40 are $A B A$ uptake transporters located in the embryo. To inhibit embryo germination, de novo biosynthesized $A B A$ is transported from the endosperm to the embryo by the four transporters. Solid arrows indicate the direction of AtABCG-mediated ABA transportation. Data are means \pm s.e.m. of $n=6(\mathbf{a}, \mathbf{b})$ or $n=4$ (c) from three or four independent experiments. $\left({ }^{\star} P<0.05 ;{ }^{* \star} P<0.01\right.$ compared with

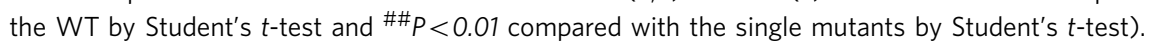

\section{Discussion}

In this study, we characterize two novel $\mathrm{ABA}$ transporter candidates, AtABCG31 and AtABCG30 (Fig. 5d), and provide various lines of evidence that the $\mathrm{ABC}$ transporters AtABCG31 and AtABCG25 mediate ABA secretion from the endosperm, and that AtABCG30 and AtABCG40 mediate ABA uptake into the 
embryo. Interestingly, although all these AtABCG transporters exhibit a common substrate transport activity, they are structurally different and not closely related in phylogenetic tree. AtABCG25 is a half-size ABC transporter, whereas AtABCG31, AtAtABCG30 and AtABCG40 are full-size ABC proteins ${ }^{52}$. Moreover, the three full-size transporters belong to different phylogenetic clusters ${ }^{52}$.

We found that AtABCG31 transcripts were present in the endosperm (Fig. 2a), which is consistent with a recent report ${ }^{53}$. Freshly collected intact atabcg31 seeds exhibited an enhanced germination phenotype in the presence (Supplementary Fig. 1c,d) or absence (Fig. 1a) of exogenous ABA. Thus, AtABCG31 appears to function as an efflux transporter that transports ABA from the endosperm to the embryo to prevent germination under unfavourable environmental conditions. AtABCG31 was previously reported to be expressed specifically in guard cells ${ }^{54}$ and the tapetum ${ }^{49}$. ABA plays an important role in both cell types, functioning in stomatal closure and pollen maturation, respectively; however, no direct link to $\mathrm{ABA}$ transport was demonstrated.

AtABCG25 was previously reported to function as an ABA exporter that was active mainly in ABA-synthesizing tissues ${ }^{39}$. Here we show that this transporter also exports $A B A$ from the endosperm (Figs 2 and 5a). Unlike AtABCG31, AtABCG25 seemed to be expressed in the embryo too (Fig. 2b). However, the expression levels of $A t A B C G 25$ in seed tissues were much lower than those of AtABCG31, and the embryonic expression level of AtABCG25 was barely above the background level. Therefore, this result either indicates that AtABCG25 is not expressed in the embryo or that it is only expressed at low levels. It is possible that low levels of AtABCG25 contribute to the proper distribution of ABA within the embryonic tissues. However, the major site of AtABCG25 function in seeds is most likely the endosperm, where it is expressed at significant levels. The observation that the double knockouts of AtABCG25 and AtABCG31 exhibited a stronger phenotype than any of the single knockouts indicates that both transporters are needed to efficiently block germination when GA levels are low and that both transporters exhibit only a limited ABA efflux capacity. In addition, the double knockouts exhibited lower PAC-induced ABA accumulation than the wild type (Supplementary Fig. 6b), suggesting that a defect in ABA secretion may have inhibited ABA biosynthesis by a negative feedback mechanism.

It is interesting to note that AtABCG40, which is broadly expressed in plants, regulates many different physiological properties, including lateral root number, main root growth, seed germination and stomatal movement ${ }^{40}$. These properties can all be explained by the transport of a single substrate, $\mathrm{ABA}^{38}$. In contrast, AtABCG30 is specifically expressed in imbibed seeds, and thus its role seems to be restricted to the inhibition of germination. Our data indicate that both AtABCG40 and AtABCG30 contribute to ABA uptake into the embryo and are required to maintain $\mathrm{ABA}$ fluxes. This is supported by former data showing ABA transport activity in heterologous systems ${ }^{40}$ and our data demonstrating that AtABCG30-expressing yeast take up far more ABA than the corresponding empty vector control (Fig. 5d). When expressed in yeast, AtABCG40 and AtABCG30 exhibited similar ABA transporting activities (Supplementary Fig. 6f). Since these two genes exhibit different expression patterns in planta, the relative contribution of each transporter to overall ABA flux changes depending on the particular tissue and developmental stage. Thus, the transporters involved in $\mathrm{ABA}$ release and uptake are not completely redundant, and all four $\mathrm{ABC}$ transporters are required to efficiently suppress seed germination. Recently, ABA-importing transporter 1 (AIT1), which is expressed mainly in the vasculature and also in the embryo, was reported to act as an ABA importer for exogenously supplied $\mathrm{ABA}^{42}$, raising the question of whether this ABA importer also suppresses embryo growth.

The four atabcg mutants studied here are in the Col-0 background, which is among the weakest in dormancy among Arabidopsis thaliana ecotypes ${ }^{16,19,55}$. As a result, we evaluated the roles of the transporters in the absence of GA synthesis, which leads to endogenous ABA accumulation ${ }^{13}$. This is because when seeds are highly dormant, GA is unable to efficiently downregulate DELLA factor accumulation, and the endosperm releases ABA in a DELLA-dependent manner to block embryonic growth $^{32}$. Therefore, it is likely that the AtABCG transporters identified in this study also serve as ABA efflux and influx transporters to block the germination of naturally dormant seeds. However, this conclusion will require further evaluation using atabcg31, atabcg25, atabcg30 and atabcg40 mutant alleles isolated in highly dormant ecotypes.

Most studies on ABA transport have sought to elucidate aspects of the plant's response to environmental stress, such as guard cell closure or long-term adaptation to drought or salinity. Thus, previous discussions on ABA transporters have focused mainly on long-distance transport from the drought-stressed root to the shoot ${ }^{56}$. However, here we have identified four ABA transporters that act in concert to regulate the developmental process of seed germination in adjacent tissues within the seed. These transporters transfer ABA from the site of ABA synthesis (the endosperm) to its target (the embryo) to prevent germination (Fig. 5e). It is plausible that other stress- and development-related responses also require the coordination of short- and longdistance transporters of $\mathrm{ABA}$, in a manner similar to the numerous auxin transporters that collaborate at short and long distances to control plant development.

\section{Methods}

Plant material and growth conditions. All Arabidopsis wild-type plants used in this study were of the Columbia- 0 ecotype. Plants as well as seed coats and embryos were incubated on $1 / 2$ Murashige-Skoog (MS) agar $(0.8 \%)$ media $\left(22 / 18^{\circ} \mathrm{C} ; 16 / 8 \mathrm{~h}\right.$ day/night; $40 \mu \mathrm{mol} \mathrm{m}^{-2} \mathrm{~s}^{-1}$ light). Experiments were performed with wild-type and mutant plants grown in parallel and seeds were collected at the same time point. Seeds were sown on $1 / 2$ MS agar $(0.8 \%)$ media and cultured for 10 days $\left(22 / 18^{\circ} \mathrm{C} ; 16 / 8 \mathrm{~h}\right.$ day/night; $40 \mu \mathrm{mol} \mathrm{m}^{-2} \mathrm{~s}^{-1}$ light $)$. Seedlings were transferred to the soil and cultured in a greenhouse $\left(22 / 18^{\circ} \mathrm{C} ; 16 / 8 \mathrm{~h}\right.$ day/night). Fully developed and ripened brown siliques were collected.

Seed germination assay. For the germination assay, 12 seeds were placed on a $0.45-\mu \mathrm{m}$ pore-size nylon membrane on $1 / 2 \mathrm{MS}$ medium and incubated at a light intensity of $40 \mu \mathrm{mol} \mathrm{m}^{-2} \mathrm{~s}^{-1}\left(16 / 8 \mathrm{~h}\right.$ day/night) at $22 / 18^{\circ} \mathrm{C}$. For the quantification, the seeds with (cold) or without (no cold) pretreatment in the dark at $4{ }^{\circ} \mathrm{C}$ for 2 days were sowed on $1 / 2$ MS medium in the absence or presence of $0.5-1.0 \mu \mathrm{M} \mathrm{ABA}$. The seeds were incubated under 16-h light and 8-h dark conditions at $22^{\circ} \mathrm{C}$.

Quantitative real time RT-PCR. Total RNA was extracted from dissected embryos or endosperms, or whole seeds of the Col-0 wild type using the RNeasy Plant Mini Kit (Qiagen). One microgram of total RNA was treated with DNAseI (Roche) to remove any residual genomic DNA. cDNA was synthesized with GoScript reverse transcriptase (Promega). qRT-PCR was performed with the SYBR Kit (TAKARA) to detect AtABCG25, AtABCG30, AtABCG31, AtABCG40, AtABI4, AtEPA1 and AtUbiqutin11 transcript levels. Amplified samples were normalized against AtUbiqutin11 levels. Primer sequences were as follows: for AtABCG25 (At1g71960), forward (5'-GAGACGCCATGGCTTACTTTGA-3') and reverse (5' -AATACATGTTGTTATTCCACCGCC-3'); for AtABCG30 (At4g15230), forward (5'-CATGGCAGTGACTCTACGCTCATCT- $\left.3^{\prime}\right)$ and reverse (5'-TTGCC ACGATAATGGGATAAGCG-3'); for AtABCG31 (At2g29940), forward (5' ${ }^{\prime}$-TCCA AAAGCCTTTGATTCCAGT- $\left.3^{\prime}\right)$ and reverse (5' ${ }^{\prime}$ TCCCACAGGACTTTTT TTATCTTCTC-3'); for AtABCG40 (Atlg15520), forward (5'-CTGAGCGAAA GCATAAGGCATG- $3^{\prime}$ ) and reverse (5'-TGGAGAAATCCTCCTTACACAGC C-3'); for AtABI4 (At2g40220), forward (5'-ATGGACCCTTTAGCTTCCCA-3') and reverse ( $5^{\prime}$-CCACTTGCGAGTGCGCTTAC- $3^{\prime}$ ); for AtEPR1 (At2g27380), forward (5'-CCACCTGTCAAGCCACCGCCAAT- $\left.3^{\prime}\right)$ and reverse (5'-GTAAGT TGGTGTCGGAGGCTTATGCA-3' ${ }^{4}{ }^{46}$; for AtUbiqutin11 (At4g05050), forward 
(5'-GAACCAAGTTCATGTATCGT- $\left.3^{\prime}\right)$ and reverse (5'-ACACTCATCAAACTA AGC AC-3') (ref. 57).

Promoter constructs. The AtABCG30 promoter::uidA reporter gene construct was generated by PCR amplification of a $2.0-\mathrm{kb}$ promoter region of AtABCG30 from genomic DNA using primers containing $\mathrm{ClaI}$ and $\mathrm{X} b a \mathrm{I}$ restriction sites $\left(5^{\prime}\right.$-ATCGATTCCACTGGCCAAATTTCTCTATACA- $3^{\prime}$ and $5^{\prime}$-TCTAGATTT CAGTTAAAATGCCAACGGAA- $3^{\prime}$ ) and ligation of the PCR product into pBI101.2 (Clontech). The AtABCG31 promoter::uidA reporter gene construct was generated by PCR amplification of a $2.5-\mathrm{kb}$ promoter region of AtABCG31 from genomic DNA using primers (5'-CTCATGTGGTAGACTGCTAA- $3^{\prime}$ and $5^{\prime}$-CTC CATACCAACTCTACGAA- $3^{\prime}$ ) and recombination of the PCR product into the pMDC163 using the Gateway System. All constructs were verified by sequencing.

\section{Intracellular localization of AtABCG31 and AtABCG30. The AtABCG30}

construct was generated by PCR amplification of a $6.2-\mathrm{kb}$ genomic DNA region of AtABCG30 from Arabidopsis genomic DNA using primers containing KpnI restriction sites (5'-GGGGTACCATGATCCAAACAGGTGAAGAAGATG-3' and $5^{\prime}$-GGTACCTTTCTTTTGGAAACTGAGTT- $3^{\prime}$ ). The resulting construct was ligated into the pART7 vector ${ }^{58}$. In the case of AtABCG31, a previously reported 35Spro::sGFP::AtABCG31 construct ${ }^{48}$ was used. Each construct was introduced into Arabidopsis mesophyll protoplasts using the polyethylene glycol method ${ }^{59,60}$ along with a plasma membrane marker PM-rK (CD3-1007, ABRE). Protoplasts were isolated from 6-week-old wild-type Arabidopsis leaves by enzyme treatments. For each transfection, $200 \mu \mathrm{l}$ cells $\left(2 \times 10^{5}\right.$ protoplasts per $\left.\mathrm{ml}\right)$ were incubated with $20 \mu \mathrm{g}$ total DNA and $220 \mu \mathrm{l} 40 \%$ (w/v) PEG4000 solution. Seventy hours after incubation under dim-light conditions, green (GFP) and red (mCherry) fluorescence signals were observed and captured using a confocal microscope (Leica TCS SP5).

Seed coat bedding assay. Detailed protocols on how to assemble SCBA can be found in Lee et al. ${ }^{33,34}$. For the SCBA, which tests the repressive activity of the endosperm, embryos were dissected from aba2-1 mutant seeds $4 \mathrm{~h}$ after imbibition $^{33}$. Twenty dissected embryos were placed on a layer of 80 seed coat beddings dissected from freshly collected mutant seeds on the surface of $10 \mu \mathrm{M}$ PAC containing $1 / 2 \mathrm{MS}$ agar medium and incubated under $40 \mu \mathrm{mol} \mathrm{m}^{-2} \mathrm{~s}^{-1}$ light (continuous light) at $22^{\circ} \mathrm{C}$.

To evaluate the embryo's capacity to uptake germination inhibitor from the endosperm, 20 dissected embryos were placed on a layer of 80 seed coat bedding dissected from dormant Cvi seeds placed on $1 / 2$ MS agar medium and incubated at a light intensity of $40 \mu \mathrm{mol} \mathrm{m}^{-2} \mathrm{~s}^{-1}$ (continuous light) at $22^{\circ} \mathrm{C}$.

For the embryonic growth assay of dissected embryos, 12 embryos dissected from wild-type (Col-0), atabcg mutant seeds or whole seeds were placed on a $0.45-\mu \mathrm{m}$ pore-size nylon membrane on $1 / 2 \mathrm{MS}$ medium in the absence or presence of $0.1 \mu \mathrm{M}$ ABA. In this experiment, we used a lower ABA concentration, since exogenously added $A B A$ inhibits the growth of dissected, coatless embryos much more effectively than it inhibits the growth of embryos in whole seeds.

Assay of secreted and remaining ABA levels. Endosperms and testa were dissected from 500 seeds of the wild type and atabcg 25 and atabcg31 singleknockout and atabcg25 atabcg31 double-knockout mutants imbibed for $24 \mathrm{~h}$ on $1 / 2$ MS agar media complemented with $10 \mu \mathrm{M}$ PAC or for $1 \mathrm{~h}$ on the same medium without PAC. To collect excreted ABA, the tissues were subsequently incubated in $100 \mu \mathrm{l} 1 / 2 \mathrm{MS}$ liquid medium without PAC for $24 \mathrm{~h}$. After incubation, the remaining tissues were washed with ice-cold $1 / 2$ MS medium. ABA was extracted with $80 \%$ methanol solution, vacuum dried and the pellet was resuspended with Tris-buffered saline buffer. ABA levels were determined using the ELISA Kit (Agdia) ${ }^{61}$.

${ }^{3} \mathbf{H}-\mathbf{A B A}$ accumulation assay. Fifty dissected embryos were incubated in $100 \mu \mathrm{l}$ of a bathing solution ( $\mathrm{pH} 6.5)$ containing $12.5 \mathrm{nM}^{3} \mathrm{H}-\mathrm{ABA}\left(1.63 \mathrm{Tbq} \mathrm{mmol}^{-1}\right)$ and $17.5 \mathrm{pM}^{14} \mathrm{C}$-glycerol $\left(5.40 \mathrm{GBq} \mathrm{mmol}^{-1}\right.$ ) for $30 \mathrm{~min}$ at room temperature. After incubation, embryos were washed three times with $250 \mu$ ice-cold bathing solution, and their radioactivity was determined by liquid scintillation counting.

\section{Heterologous expression of AtABCGs and ABA loading assays. AtABCG31} cDNA was cloned into the NotI and XbaI sites of pYES2NT/C (Invitrogen). AtABCG30 cDNA was cloned into the KpnI and XbaI sites of pYES2NT/C. All constructs were verified by sequencing. AtABCGs expressing yeast lines were generated using the electroporation method and selected on uracil-minus minimal media. ${ }^{3} \mathrm{H}$-ABA-loading tests were performed as described previously with minor modification ${ }^{40}$. Cells were cultured in minimum salt-galactose medium in the absence of uracil (SG-URA), supplemented with $1.0 \%$ raffinose, at $\mathrm{pH} 6.5$, and collected by centrifugation at the mid-log phase (up to $\mathrm{OD}_{600}=1.0$ ). Yeast cells were washed two times using SG-URA medium and subsequently resuspended in reaction buffer ( $1 \mathrm{mM} \mathrm{KCl}, 1 \mathrm{mM}$ MES (2-(N-morpholino) ethanesulfonic acid), $20 \mathrm{mM}$ glucose, at $\mathrm{pH} 6.5)$ at an $\mathrm{OD}_{600}=10 .{ }^{3} \mathrm{H}-\mathrm{ABA}(50 \mathrm{nM}, 7.4 \mathrm{kBq}$,

$1.63 \mathrm{TBq} \mathrm{mmol}^{-1}$ ) was then added to the cell suspension and gently mixed. At the times indicated, $100 \mu \mathrm{l}$ of cell suspension was filtered through nitrocellulose membranes, and the cells remaining on the filter were washed two times with $2 \mathrm{ml}$ of ice-cold water. The radioactivity on the filter was determined using a liquid scintillation counter.

\section{References}

1. Hilhorst, H. W. M. A critical update on seed dormancy. I. Primary dormancy. Seed Sci. Res. 5, 61-73 (1995).

2. Bewley, J. D. Seed germination and dormancy. Plant Cell 9, 1055-1066 (1997).

3. Kucera, B., Cohn, M. A. \& Leubner-Metzger, G. Plant hormone interactions during seed dormancy release and germination. Seed Sci. Res. 15, 281-307 (2005).

4. Holdsworth, H. J., Bentsink, J. \& Soppe, W. J. J. Molecular networks regulating Arabidopsis seed maturation, after-ripening, dormancy and germination. New Phytol. 179, 33-54 (2008).

5. Seo, M. et al. Interaction of light and hormone signals in germinating seeds. Plant Mol. Biol. 69, 463-472 (2009).

6. Graeber, K. et al. Molecular mechanisms of seed dormancy. Plant Cell Environ. 35, 1769-1786 (2012).

7. Nonogaki, H. Seed dormancy and germination-emerging mechanisms and new hypotheses. Front. Plant Sci. 5, 233 (2014).

8. Hilhorst, H. W. M. \& Karssen, C. M. Seed dormancy and germination: the role of abscisic acid and gibberellins and the importance of hormone mutants. Plant Growth Regul. 11, 225-238 (1992).

9. Debeaujon, I. \& Koornneef, M. Gibberellin requirement for Arabidopsis thaliana seed germination is determined both by testa characteristics and embryonic ABA. Plant Physiol. 122, 415-424 (2000).

10. Toh, S. et al. High temperature-induced abscisic acid biosynthesis and its role in the inhibition of gibberellin action in Arabidopsis seeds. Plant Physiol. 146, 1368-1385 (2008).

11. Verslues, P. E. \& Bray, E. A. Role of abscisic acid (ABA) and Arabidopsis thaliana $\mathrm{ABA}$-insensitive loci in low water potential-induced $\mathrm{ABA}$ and proline accumulation. J. Exp. Bot. 57, 201-212 (2006).

12. Piskurewicz, U., Turecková, V., Lacombe, E. \& Lopez-Molina, L. Far-red light inhibits germination through DELLA-dependent stimulation of ABA synthesis and ABI3 activity. EMBO J. 28, 2259-2271 (2009).

13. Piskurewicz, U. et al. The gibberellic acid signaling repressor RGL2 inhibits Arabidopsis seed germination by stimulating abscisic acid synthesis and ABI5 activity. Plant Cell 20, 2729-2745 (2008).

14. Finch-Savage, W. E. \& Leubner-Metzger, G. Seed dormancy and the control of germination. New Phytol. 171, 501-523 (2006).

15. Lopez-Molina, L., Mongrand, S., MeLachlin, D. T., Chait, B. T. \& Chua, N. $\mathrm{ABI} 5$ acts downstream of $\mathrm{ABI} 3$ to execute an ABA-dependent growth arrest during germination. Plant J. 32, 317-328 (2002).

16. Ali-Rachedi, S. et al. Changes in endogenous abscisic acid levels during dormancy release and maintenance of mature seeds: studies with the Cape Verde Islands ecotype, the dormant model of Arabidopsis thaliana. Planta 219, 479-488 (2004).

17. Robertson, D. S. The genetics of vivipary in maize. Genetics 40, 745-760 (1955).

18. Van der Schaar, W. et al. QTL analysis of seed dormancy in Arabidopsis using recombinant inbred lines and MQM mapping. Heredity 79, 190-200 (1997).

19. Koornneef, M., Bentsink, L. \& Hilhorst, H. W. M. Seed dormancy and germination. Curr. Opin. Plant Biol. 5, 33-36 (2005).

20. Preston, J. et al. Temporal expression patterns of hormone metabolism genes during imbibition of Arabidopsis thaliana seeds: a comparative study on dormant and non-dormant accessions. Plant Cell Physiol. 50, 1786-1800 (2009).

21. Alonso-Blanco, C. et al. Analysis of natural allelic variation at seed dormancy loci of Arabidopsis thaliana. Genetics 164, 711-729 (2003).

22. Bentsink, L. et al. Natural variation for seed dormancy in Arabidopsis is regulated by additive genetic and molecular pathways. Proc. Natl Acad. Sci. USA 107, 4264-4269 (2010).

23. Teng, S., Rognoni, S., Bentsink, L. \& Smeekens, S. The Arabidopsis GSQ5/ DOG1 Cvi allele is induced by the ABA-mediated sugar signaling pathway, and enhances sugar sensitivity by stimulating ABI4 expression. Plant J. 55, 372-381 (2008).

24. Muller, K., Tintelnot, S. \& Leubner-Metzger, G. Endosperm-limited Brassicaceae seed germination: abscisic acid inhibits embryo-induced endosperm weakening of Lepidiumsativum (cress) and endosperm rupture of Cress and Arabidopsis thaliana. Plant Cell Physiol. 47, 864-877 (2006).

25. Bethke, P. C. et al. The Arabidopsis aleurone layer responds to nitric oxide, gibberellin, and abscisic acid and is sufficient and necessary for seed dormancy. Plant Physiol. 143, 1173-1188 (2007).

26. Kelly, K. M. et al. Seed coat structure and dormancy. Plant Growth Regul. 11, 201-209 (1992).

27. Karssen, C. M. et al. Induction of dormancy during seed development by endogenous abscisic acid: studies on abscisic acid deficient genotypes of Arabidopssi thaliana (L.) Heynh. Planta 157, 158-165 (1983). 
28. Koornneef, M. et al. In vivo inhibition of seed development and reserve protein accumulation in recombinants of abscisicacid biosynthesis and responsiveness mutants in Arabidopsis thaliana. Plant Physiol. 90, 463-469 (1989).

29. Barrero, J. M. et al. Gene expression profiling identifies two regulatory genes controlling dormancy and ABA sensitivity in Arabidopsis seeds. Plant J. 61, 611-622 (2010).

30. Bassel, G. W., Mullen, R. T. \& Bewley, J. D. ABI3 expression ceases following, but not during, germination of tomato and Arabidopsis seeds. J. Exp. Bot. 57, 1291-1297 (2006)

31. Penfield, S., Li, Y., Gilday, A. D., Graham, S. \& Graham, I. A. Arabidopsis ABA insensitive 4 regulates lipid mobilization in the embryo and reveals repression of seed germination by the endosperm. Plant Cell 18, 1887-1899 (2006).

32. Lee, K. P., Piskurewicz, U., Tureckova, V., Strnad, N. \& Lopez-Molina, L. A seed coat bedding assay shows that RGL2-dependent release of abscisic acid by the endosperm controls embryo growth in Arabidopsis dormant seeds. Proc. Natl Acad. Sci. USA 107, 19108-19113 (2010).

33. Lee, K. P. et al. Spatially and genetically distinct control of seed germination by phytochromes A and B. Genes Dev. 26, 1984-1996 (2012).

34. Lee, K. P. \& Lopez-Molina, L. A seed coat bedding assay to genetically explore in vitro how the endosperm controls seed germination in Arabidopsis thaliana. J. Vis. Exp. 81, e50732 (2013).

35. Salisbury, F. B. Plant Physiology, 3rd edn. 312 (1985).

36. Marchant, A. et al. AUX1 regulates root gravitropism in Arabidopsis by facilitating auxin uptake within root apical tissues. EMBO J. 18, 2066-2073 (1999).

37. Vieten, A., Sauer, M., Brewer, P. B. \& Friml, J. Molecular and cellular aspects of auxin-transport-mediated development. Trends Plant Sci. 12, 160-168 (2007).

38. Swarup, K. et al. The auxin influx carrier LAX3 promotes lateral root emergence. Nat. Cell Biol. 10, 946-954 (2008).

39. Kuromori, T. et al. ABC transporter AtABCG25 is involved in abscisic acid transport and responses. Proc. Natl Acad. Sci. USA 107, 2361-2366 (2010).

40. Kang, J. et al. PDR-type ABC transporter mediates cellular uptake of the phytohormone abscisic acid. Proc. Natl Acad. Sci. USA 107, 2355-2360 (2010).

41. Kuromori, T. et al. Arabidopsis mutants of AtABCG22, an ABC transporter gene, increase water transpiration and drought susceptibility. Plant J. 67, 885-894 (2011).

42. Kanno, Y. et al. Identification of an abscisic acid transporter by functional screening using the receptor complex as a sensor. Proc. Natl Acad. Sci. USA 109, 9653-9658 (2012).

43. Leran, S. et al. A unified nomenclature of NITRATE TRANSPORTER 1/PEPTIDE TRANSPORTER family members in plants. Trends Plant Sci. 19, 5-9 (2014).

44. Zhang, H. et al. A DTX/MATE-type transporter facilitates abscisic acid efflux and modulates ABA sensitivity and drought tolerance in Arabidopsis. Mol. Plant 7, 1522-1532 (2014).

45. Jasinski, M. et al. A plant plasma membrane ATP binding cassette-type transporter is involved in antifungal terpinoid secretion. Plant Cell 13, 1095-1107 (2001).

46. Dubreucq, B. et al. The Arabidpsis AtEPR1 extnesin-like gene is specifically expressed in endosperm during seed germination. Plant J. 23, 643-652 (2000).

47. Lee, M. et al. AtPDR12 contributes to lead resistance in Arabidopsis. Plant Physiol. 138, 827-836 (2005).

48. Nelson, B. K., Cai, X. \& Nebenfuhr, A. A multicolored set of in vivo organelle markers for co-localization studies in Arabidopsis and other plants. Plant J. 51, 1126-1136 (2007).

49. Choi, H. et al. The role of Arabidopsis ABCG9 and ABCG31 ATP binding cassette transporters in pollen fitness and the deposition of steryl glycosides on the pollen coat. Plant Cell 26, 310-324 (2014).

50. Lee, K. P. \& Lopez-Molina, L. Control of seed germination in the shade. Cell Cycle. 11, 4489-4490 (2012)

51. Leon-Kloosteriel, K. M. et al. Isolation and characterization of abscisic aciddeficient Arabidopsis mutants at two new loci. Plant J. 10, 655-667 (1996).
52. Andolfo, G. et al. Genetic variability and evolutionary diversification of membrane ABC transporters in plants. BMC Plant Biol. 15, 51 (2015).

53. Dekkers, B. J. W. et al. Transcription dynamics of two seed compartments with opposing roles in Arabidopsis seed germination. Plant Physiol. 163, 205-215 (2013).

54. Galbiati, M. et al. Gene trap lines identify Arabidopsis genes expressed in stomatal guard cells. Plant J. 53, 750-762 (2008).

55. Koornneef, M. et al. in Dormancy in Plants. (eds Viémont, J.-D \& Crabbé, J.) Ch. 5, 365-373 (Oxon:CABI publishing, 2000).

56. Jiang, F. \& Hartung, W. Long-distance signaling of abscisic acid (ABA): the factors regulating the intensity of the ABA signal. J. Exp. Bot. 59, 37-43 (2007).

57. Gutierrez, L. et al. The lack of a systematic validation of reference genes; a serious pitfall undervalued in reverse transcription polymerase chain reaction (RT-PCR) analysis in plants. Plant J. 6, 609-618 (2008).

58. Gleave, A. P. A versatile binary vector system with a T-DNA organizational structure conducive to efficient integration of cloned DNA into the plant genome. Plant Mol. Biol. 20, 1203-1207 (1992).

59. Abel, S. \& Theologi, A. Transient gene expression in protoplasts of Arabidopsis thaliana. Methods Mol Biol. 82, 209-217 (1998).

60. Jin, J. et al. A new dynamin-like protein, ADL6, is involved in trafficking from the trans-Golgi network to the central vacuole in Arabidopsis. Plant Cell 13, 1511-1525 (2001).

61. Jiang, T. et al. Root morphology and gene expression analysis in response to drought stress in maize (Zea mays). Plant Mol. Biol. Rep. 30, 360-369 (2012).

\section{Acknowledgements}

This work was supported by the National Research Foundation (NRF) grants funded by the Ministry of Science, ICT (Information and Communication Technology) and Future Planning of Korea (K20607000006, 2015R1A2A1A01004294, and BK21 Plus;10Z20130012243). The work in the laboratory of E.M. was partially supported by the Swiss National Science Foundation and the Forschungskredit from Universität zürich. L.L.-M. is supported by grants from the Swiss National Science Foundation and by the State of Geneva.

\section{Author contributions}

J.K., L.L.-M. and Y.L. designed the experiments; J.K. and S.Y. performed most of the experiments; H.C. and A.K. generated some of the constructs used and transgenic plants; K.P.L., E.M. and L.L.-M. provided technical support and conceptual advice; J.K., E.M., L.L.-M. and Y.L. wrote the manuscript.

\section{Additional information}

Supplementary Information accompanies this paper at http://www.nature.com/ naturecommunications

Competing financial interests: The authors declare no competing financial interests.

Reprints and permission information is available online at http://npg.nature.com/ reprintsandpermissions/

How to cite this article: Kang, J. et al. Abscisic acid transporters cooperate to control seed germination. Nat. Commun. 6:8113 doi: 10.1038/ncomms9113 (2015).

This work is licensed under a Creative Commons Attribution 4.0 International License. The images or other third party material in this article are included in the article's Creative Commons license, unless indicated otherwise in the credit line; if the material is not included under the Creative Commons license, users will need to obtain permission from the license holder to reproduce the material To view a copy of this license, visit http://creativecommons.org/licenses/by/4.0/ 